\section{Years of Cocaine Addiction}

SIR: Rollin's fascinating description of Sherlock Holmes (Journal, August 1988, 153, 241-242) prompted us to put pen to paper. He writes that "mental or physical deterioration is the inevitable penalty of prolonged cocaine abuse." However, we have in our care a patient who has been addicted to cocaine for 50 years and has not suffered any physical, mental, or social deterioration during this period.

Clatterbridge Hospital

Bebington, Wirral

Merseyside L63 4JY

\section{Shoplifting as a Symptom of Stress in Families of Mentally Handicapped Persons: A Case Report}

SIR: Roy (Journal, June 1988, 152, 845-846) described a father of a severely handicapped schoolleaver who began to shoplift in apparent response to his son's psychiatric symptoms. Based on this case and others he did not describe, Roy claimed that shoplifting is a symptom of "stress" in families of the mentally handicapped. I would disagree with this view, if it is based largely on the presented case, as the father was "severely depressed", being referred for treatment of his depression.

It is well known that a large percentage of women who shoplift are depressed (Gibbens, 1971), with the most frequent diagnosis being depressive neurosis (Bradford \& Balmaceda, 1983). Gibbens (1971) claims that shoplifting may be the earliest symptom of depression in these women. Additionally, Fishbain (1987) has recently presented case evidence that indicates that the risk-taking of shoplifting may be important to kleptomaniac behaviour. Risk-taking behaviour has been found to have an antidepressant effect in depressed young males (Parker \& Brown, 1979). Thus Fishbain (1987) has postulated that in his patient depression served as a stimulus to the kleptomaniac behaviour, which in turn had an antidepressant effect through a symptom relief mechanism (Coid, 1984). I wonder if this same mechanism, rather than "stress", could be a more precise explanation for the father's shoplifting?

Comprehensive Pain and

David Fishbain

Rehabilitation Center

600 Alton Road

Miami Beach, FL 33139, USA

\section{References}

Bradford, J. \& BAlmaceda, R. (1983) Shoplifting: is there a specific psychiatric syndrome? Canadian Journal of Psychiatry, 28, 248-253.

ColD, J. (1984) Relief of diazepam withdrawal syndrome by shoplifting. British Journal of Psychiatry, 145, 552-554.

FishBaIN, D. A. (1987) Kleptomania as risk-taking behaviour in response to depression. Australian Journal of Psychotherapy. 41, 598-603.

GibBens, T. C. N. (1971) Mental health aspects of shoplifting. British Medical Journal, iii, 612-615.

PARKer, G. \& Brown, L. B. (1979) Repertoires of response to potential precipitants of depression. Australian and New Zealand Journal of Psychiatry, 13, 327-333.

\section{Auditory Hallucinations Due to Ear Disease}

SIR: Following the recent correspondence concerning unilateral auditory hallucinations and ear disease (Khan et al, Journal, February 1988, 152, 297-298; Gordon, Journal, August 1988, 153, 263-264; McBride and Hamilton-Kirkwood, Journal, August $1988,153,264)$, it is worth noting that complex auditory hallucinations may also complicate bilateral ear disease, since it is under these circumstances that confusion with psychiatric disease is most likely to occur.

Case Report: An 83-year-old widow with longstanding deafness abruptly developed auditory hallucinations, which she recognised as "Harry Lime and His Orchestra" repeatedly playing a medley of songs from her youth, including favourites like "Horsie Keep Your Tail Up" and "Hold Your Hand Out You Naughty Boy". She initially thought the music was coming from an external source, such as neighbours playing a tape, but came to realise it was not real. She heard the music for long periods, and it often woke her from sleep. She had been treated for reactive depression two months earlier after the death of her pet dog, but at the time of her auditory hallucinations she had no psychiatric symptoms. She had a past medical history of atrial fibrillation and mild asymptomatic IgM paraproteinaemia. Neurological examination, including psychometry, was normal apart from moderate $(50-60 \mathrm{~dB})$ bilateral sensorineural deafness. A CT brain scan showed a small subcortical infarct in the left parietal lobe. Her symptoms were unchanged one year later.

The association between deafness and auditory hallucination has long been recognised (Rhein, 1913); several similar cases have been reported in recent years (Ross et al, 1975; Miller and Crosby, 1979; Hammeke et al, 1983) and the phenomenon is probably commoner than is generally appreciated (Ross, 1978). It is characterised by the development of repetitive musical hallucinations (usually of familiar tunes with occasional unformed noises) in elderly patients with longstanding bilateral deafness. 